\author{
Pau Freixa Terradas \\ Universitat de Barcelona \\ Akademia Techniczno-Humanistyczna w Bielsku-Białej \\ paufreixa@ub.edu
}

\title{
Jorge Luis Borges en Danilo Kiš o La lección intertextual
}

\section{Jorge Luis Borges in Danilo Kis or The Intertextual Lesson}

\begin{abstract}
Few authors of the 20th century have had such a remarkable influence on the literature of other writers as Jorge Luis Borges. The impact of his works can be appreciated in all important national literatures; many writers have recognized his expertise and influence, some of them openly imitating him. In this respect, literature written in Serbo-Croatian is a special case, with a huge reception of his literature. The Borges "wave" arrived late to Yugoslavia, but with increased strength, and from the 1970s on the Argentinean author has remained one of the favourite writers amongst young readers. Local writers quickly absorbed all the aesthetic and conceptual developments of the author of Ficciones, even giving birth to a new trend called "Borgesian prose" which has given the world such remarkable authors as Milorad Pavić. Although not considered strictly a borgesist, Danilo Kišs, one of the internationally best known Serbian authors, deserves special attention. Much of his work is marked in many ways by Borgesian stylistic and thematic influences. Numerous intertextualities make some of his texts a genuine dialogue with the Argentinean master. However, the high quality, originality and diversity of Kišs work distinguish the Serbian author from the rest of the Balkan Borges' followers. The present paper reviews the influences, references, allusions, appropriations and other intertextual links to Borges' literature that can be found in works by Kiš, from his first novels, where the influence is more subdued, through numerous references in A tomb for Boris Davidovich, to the already clearly Borgesian stories of The Encyclopaedia of the Dead.
\end{abstract}

Keywords: comparative literature, Jorge Luis Borges, Danilo Kišs, Serbian literature, intertextuality, reception and effect studies

Streszczenie: Niewielu dwudziestowiecznych autorów miało tak znaczny wpływ na literaturę innych pisarzy jak Jorge Luis Borges. Inspiracje jego dziełami widoczne są we wszystkich ważnych literaturach narodowych, a wielu pisarzy otwarcie uznaje jego kompetencje i wpływ, a niektórzy z nich wręcz otwarcie go imitują. W tym aspekcie szczególnym przypadkiem jest literatura w języku serbsko-chorwackim, która na wielką skalę czerpała z jego twórczości. Fala fascynacji Borgesem dotarła do Jugosławii późno, ale za to ze zdwojoną siłą i od 1970 roku argentyński autor stał się jednym z ulubionych pisarzy młodych czytelni- 
ków. Lokalni twórcy szybko przyswoili sobie wszystkie estetyczne i konceptualne innowacje autora Fikcji, dając nawet początek nowemu nurtowi literackiemu znanemu jako „proza borgesowska”, który wydał pisarzy tak wyjątkowych jak Milorad Pavić. Na szczególną uwagę zasługuje Danilo Kišs, który choć nie jest uznawany sensu stricto za borgesistę, jest jednym z najbardziej uznanych serbskich pisarzy. W większości jego dzieł widoczne są stylistyczne i tematyczne wpływy Borgesa. Liczne odniesienia intertekstualne zmieniają jego teksty w prawdziwy dialog z argentyńskim mistrzem. Wysoka jakość, oryginalność i różnorodność jego prac są tym, co wyróżnia tego serbskiego autora spośród innych bałkańskich epigonów Borgesa. Prezentowany tu artykuł ma na celu analizę wpływów, odniesień, aluzji, zapożyczeń i innych środków intertekstualnych pochodzących z twórczości Borgesa obecnych w książkach Kiša, od jego pierwszych powieści, w których wpływy te są jeszcze bardzo dyskretne, aż po wyraźnie borgesowskie opowiadania z tomu Encyklopedia zmartych czy liczne referencje obecne w Grobowcu dla Borisa Dawidowicza.

Słowa kluczowe: komparatystyka, Jorge Luis Borges, Danilo Kiš, literatura serbska, intertekstualność, studia nad odbiorem i efektem

El arte narrativo se divide en el que habia antes de Borges y el de después de Borges.

Danilo Kiš, Lección de anatomía

\section{A modo de introducción}

Pocos autores como Jorge Luis Borges han dejado una obra tan original y relevante para el desarrollo posterior de la literatura universal. Aunque a menudo se afirma que la cultura y las letras occidentales aún no han digerido completamente las inmensas aportaciones del escritor argentino, la influencia de su obra es desde hace medio siglo de las que más claramente se percibe en el arte de otros autores y hasta en el transcurso general del pensamiento de la segunda mitad del siglo XX. A menudo declarado creador de la posmodernidad literaria, Borges desencadenó con su obra narrativa un ejército de imitadores y también algún digno epígono que encontramos prácticamente en cualquier tradición literaria a lo largo y ancho del globo terráqueo. A partir de la aparición de las primeras traducciones de su obra, a caballo entre los años 50 y 60, se comenzará a notar la influencia de la lectura de sus textos y poco a poco irán apareciendo una serie de continuadores de su poética.

Por lo que se refiere a los entonces comunistas países del Este europeo, la aparición a principios de los años 70 de exhaustivas colecciones de literatura iberoamericana contemporánea, así como la entusiasta acogida que tuvieron entre un público muy pendiente de la realidad social y política del continente americano, despertaron en muchos de los países eslavos una gran admiración por autores como Borges, Cortázar, García Márquez, Donoso o Onetti, entre otros. Los títulos más populares de estas extensas colecciones desaparecían rápidamente de las librerías y los escritores locales se iban impregnando rápid- 
amente de los aires renovadores que llegaban de América. Entre los autores suramericanos, uno de los que dejó más impronta en las diferentes literaturas eslavas fue sin duda Borges. En este sentido, un caso paradigmático lo constituyen las literaturas en lengua serbo-croata de la antigua Yugoslavia, donde incluso apareció en los ańos 70 una corriente (y también una tendencia general entendida de forma más amplia) llamada 'prosa borgiana', que se extiende hasta nuestros días (Goran Velikić, Goran Petrović) y que ha dejado nombres tan fundamentales para la literatura contemporánea como Milorad Pavić, creador del célebre Diccionario Jázaro. De entre todos los que recogieron el amplio legado de Borges destaca el escritor serbio Danilo Kiš que, a pesar de no ser de los escritores considerados más 'borgianos' en su país, ha visto a menudo comparada su literatura a la del maestro argentino y a quien la crítica francesa ha dado en llamar 'Borges de los Balcanes'. A pesar de este apodo, tan flamante como ridículo, la obra de Kiš constituye una poética propia y diferenciada de la cual sólo ciertas obras muestran parecidos evidentes con la obra narrativa de Borges y en la cual otras influencias como las de James Joyce, Bruno Schulz o el Nouveau Roman francés ocupan también un lugar preeminente. De hecho, la Historia de la literatura yugoslava nunca lo incluyó entre los llamados borgesistas de los años 70 y $80^{2}$.

Aún así, es innegable que la etapa de madurez de su creación está llena de referencias, intertextos dialógicos y alusiones a la obra de Borges y que su estilo se acerca tanto en la forma como en el contenido al del maestro ciego. Así, el nombre de Kiš aparece a menudo ligado al del argentino y son muchos los críticos que han comparado a maestro y epígono llegando a conclusiones diversas, desde la negación de semejanzas considerables por parte de Joseph Brodsky ${ }^{3}$, hasta la afirmación de Lakis Proguidis ${ }^{4}$ de que en ciertos aspectos el serbio habría superado al argentino.

Aprovechando la restitución de este gran autor serbio muerto en París en 1989 que se está llevando a cabo a nivel mundial y también en el mundo hispánico con la edición o reedición de prácticamente toda su obra de ficción al castellano parece haber llegado el momento de revisar su poética desde una perspectiva hispánica y confrontarla con la de un autor que por proximidad lingüística y cultural conocemos mejor. Desde este punto de vista, el trabajo que aquí presentamos se propone presentar al autor de obras tan fundamentales como Una tumba para Boris Davidovich al lector iberoamericano, repasando varias de las influencias más visibles que la obra de J.L. Borges dejó en varios de sus libros.

1 Temps de l'Histoire, études sur Danilo Kiš, ed. A. Prstojević, Paris-Budapest-Torino 2003.

2 J. Wierzbicki, "Serbska proza", Literatura na Świecie 1988, no 198.

3 J. Brodsky, Introduction [in:] D. Kiš, A tomb for Boris Davidovich, New York 1980.

${ }^{4}$ L. Proguidis, Danilo Kiš, portrait de famille [en:] Danilo Kiš, romancier européen, L'Atelier du roman $1996, \mathrm{n}^{\circ} 8$, http://www.vox-poetica.com/ecrivains/KIS/proguidis01.htm, Consulta: 6.03.2017. 


\section{Primeros libros}

No sabemos cuándo Danilo Kiš leyó por primera vez a Jorge Luis Borges. Como era traductor y ya por los primeros 60 iba a menudo a Francia, es de suponer que conoció sus cuentos antes de que apareciesen en la colección yugoslava Južnoamerička književnost. En cualquier caso, cuando en los 60 Kiš empieza a escribir, las posibles semejanzas con Borges resultan vagas y más bien esporádicas. Desde La buhardilla y Salmo 44, sus primeras novelas, aparecidas conjuntamente en 1962, Kiš se inscribe de lleno en la corriente renovadora de la literatura serbia junto a Miodrag Bulatović y Borislav Pekić. Esta tendencia preocupada por las innovaciones formales, la originalidad y los aspectos estéticos, busca crear nuevos caminos de expresión literaria basándose en modelos contemporáneos occidentales y en autores yugoslavos del periodo de Entreguerras como Miloš Crnjanski. Cuando Kiš escribe La buhardilla acaba de graduarse como primer comparatista de Yugoslavia en la recién creada licenciatura de literatura comparada de la Universidad de Belgrado y desea introducir en la literatura serbia todas las nuevas técnicas e inquietudes que van apareciendo en estos ańos en el Occidente europeo y en América, así como aportar su propia palabra. Ya en esta primera nouvelle aparecen elementos típicos de la posmodernidad borgiana como el juego intertextual, la condensación de estilo, la enumeración bibliográfica o un esteticismo auto-irónico.

Los siguientes diez años Kiš los consagra a la creación de la trilogía autobiográfica conocida como Circo familiar, formado por el libro de relatos Penas precoces y las novelas Jardin, cenizas - de la cual Brodsky ${ }^{5}$ afirmaría que era "a veritable gem of lyrical prose, the best book produced in the Continent in the post-war period" - y la muy aplaudida en Yugoslavia en el momento de su publicación El reloj de arena. Kiš dedicó todo este ciclo a rememorar sus años de infancia y la figura de su padre, desaparecido en Auschwitz, analizando la relación del hombre moderno con la Historia de su tiempo, tema predilecto de Kiš a lo largo de su obra y también en cierta manera de Borges, aunque de forma más abstracta.

De hecho, algunos críticos señalan ya las primeras marcas de la influencia de Borges ya en Jardin, cenizas y muy especialmente en El reloj de arena, aunque éstas son en todo caso muy discutibles. Uno de los elementos distintivos de la prosa de Borges que se perciben en estas obras es la microfocalización -un gusto por el detalle verdaderamente hipertrófico en el caso del serbio-, técnica impresionista que el argentino explotó de forma considerable. De todas formas, como señala Aleksandar $\mathrm{Hemon}^{7}$, la génesis de este gusto por el detalle y el microfoco parecen provenir más bien de la lectura obsesiva

\footnotetext{
5 J. Brodsky, op. cit., p. XII.

${ }^{6}$ Ibídem.

A. Hemon, "Reading Danilo Kiš", Context 2001, no 9.
} 
de los cuentos de Bruno Schulz que no de las de Jorge Luis Borges. La incorporación en El reloj de arena de textos y paratextos ajenos (tanto documentos como apócrifos) también es una característica plenamente borgiana. No obstante, no será hasta mediados de la década de los 70 cuando Kiš comience a dialogar de forma más abierta y explícita, como lo harán también otros autores yugoslavos de la época, con la escritura del autor argentino.

\section{Una tumba para Boris Davidovich}

Después del éxito rotundo que significó en Yugoslavia la aparición de $E l$ reloj de arena, Danilo Kiš anuncia un cambio radical en su literatura con el abandono de la temática familiar ( $\tan$ en boga las primeras décadas de posguerra, tanto entre escritores realistas como entre renovadores) y la adopción de nuevos materiales. En esta época Kiš vive a caballo entre Belgrado y Francia, donde ejerce de lector de lengua serbo-croata en diferentes universidades. Sus numerosos contactos con la izquierda francesa y la obstinada testarudez de éstos en su admiración hacia la Unión Soviética le llevarán a escribir un libro de denuncia que desenmascare los crímenes del estalinismo durante la época del 'Gran terror'. En aquellos años habían ido apareciendo los primeros documentos y novelas denunciando el sistema GULag que aportaban la versión soviética del Holocausto a la ya larga lista de obras de literatura concentracionaria de los campos nazis. Pero Kiš quería para su novela una forma de expresión nueva que condensase en sus páginas, por un lado, todo el dolor sufrido por millones de personas en los campos siberianos y, por otro, mostrase la cara oscura del carácter de la revolución, en especial la rusa. Para conseguir sus objetivos Kiš se aleja de los preceptos y procedimientos clásicos de la literatura de los campos para crear una de las obras más originales del género y por extensión de las letras yugoslavas (a menudo se ha dicho que Una tumba para Boris Davidovich es la primera novela posmoderna de esta tradición nacional) y europeas. Mientras que el título responde claramente a Un día de Iván Denisovich de Alexander Solzhenitsyn, primera novela rusa de denuncia de los GULag en aparecer en Occidente, la estructura y el estilo escogidos por Kiš para tratar este escabroso y delicado tema nos recuerdan a Borges y muy concretamente a su libro de relatos Historia universal de la infamia ${ }^{8}$.

En primer lugar, Kiš parece adaptar la estructura formal de la Historia universal de la infamia, con la unidad temática de los cuentos, que pueden leerse casi como una novela, pero también de forma autónoma, con las estructuras clásicas del género, pero formados por vińetas, que a su vez pueden funcionar también como pequeños poemas en prosa autónomos. Asimismo, abun-

${ }^{8}$ A. Prstojević, "Un certain goût de l'archive. Sur l'obsession documentaire de Danilo Kiš", Cahiers du CIM 2002, n’ 6. 
dan en Una tumba para Boris Davidovich los paratextos, las notas bibliográficas y el estilo tiene reflejos pseudo-científicos. Desde joven, Kiš iba cultivando una gran devoción por las enciclopedias y el documento histórico y consideraba las originales técnicas borgianas para dar verosimilitud al texto como óptimas para la novela histórica. Pero si bien la "historicidad" de Borges es puro artificio y está formada a menudo por textos apócrifos, Kiš opta por situar sus cuentos en una realidad dada muy concreta y recupera historias verdaderas perfectamente documentadas. A pesar de su estilo cargado y lírico, Kiš se sitúa en las antípodas de la ficción. Y es aquí donde el diálogo se vuelve polémica. Si bien los dos libros nos presentan episodios ejemplares de la Historia universal de la infamia donde la manipulación, el absurdo, la abyección y la falsedad se convierten en norma de la Historia, en el caso de Borges la denuncia nos lleva a dudar de cualquier documento histórico, mientras que en Kiš, donde estos episodios se insieren en el marco del gran terror soviético, no cabe duda de que aquí todas las historias son ciertas. Así sucedieron. La realidad supera la ficción.

Aparte del juego dialógico con las tesis de Borges que nos propone Kiš en Una tumba para Boris Davidovich, encontramos ya una serie de técnicas e ideas claramente borgianas. Para empezar, la intertextualidad que busca el juego con el lector cómplice y el diálogo con obras anteriores, hipertrofiada en la obra de Borges, explota en Kiš con la incorporación directa de fragmentos enteros de otras obras. En este sentido, el autor serbio comprendió perfectamente la lección borgiana sobre el carácter cíclico, repetitivo, de la Historia (y de los textos) y fue muy valiente en introducir un relato entero-Libros y perros, documento real de la Francia del siglo XIV que da fe de la crudeza de un pogromo- que dialoga con los otros cuentos de la novela-especialmente con el relato que da título a toda la obra- y completa su sentido general reforzando tanto desde la forma como desde el contenido la tesis del carácter cíclico de la Historia y en este caso concreto de la revolución y su naturaleza destructiva y macabra.

Desgraciadamente la crítica yugoslava de su tiempo no se percató del mensaje que Kiš quería transmitir (como tampoco fue comprendido Borges en un sentido similar por la crítica de su época) y lo acusaron de plagio. En primer lugar, algunos críticos consideraban el hecho de que los episodios fueran reales como una falta de imaginación del autor (en el caso de una novela histórica convencional seguramente no hubiera sido así, pero sí en el caso de una obra de tesis tan sui generis y genuinamente estética como Una tumba para Boris Davidovich). En segundo lugar, veían plagio en el relato externo Libros y perros introducido íntegramente y también en el estilo, tomado de autores tan dispares como Joyce, Borges, Solzhenitsyn, Nadezhda Mandelshtam o (el historiador) Roy Medvédev. Al final la polémica degeneró en una gran contienda entre detractores y defensores de Kiš que duró más de dos años y provocó un proceso penal contra Danilo Kiš y Predrag Matvejević con el con- 
sulado ruso de por medio, que por poco no les cuesta el ingreso en prisión. Además de convertirse en el mayor affaire que haya visto jamás la Historia de las letras en serbo-croata y de haber destrozado la ya de por si frágil salud de Kišs, esta polémica produjo aún dos libros de crítica literaria: la magistral Lección de anatomía de Kiš (1977), en autodefensa, y Un Narciso sin rostro, la respuesta de Dragan Jeremić (1981), presidente de la asociación de escritores de Yugoslavia, iniciador de la polémica.

Precisamente en esta Lección de anatomía Kiš nos da muchas claves sobre sus influencias borgeanas. Más allá de una acerba autodefensa o más bien contrataque, el libro es un auto-comentario de algunos de los procedimientos literarios - precisamente aquellos por los que fue acusado de plagio- presentes en Una tumba para Boris Davidovich e indirectamente se convierte en un tratado teórico sobre la utilización de citas como material literario y la citación de las fuentes, el uso del documento en obras de ficción, la técnica literaria del montaje o collage y en general sobre la circulación de los textos y la intertextualidad en la literatura moderna. Como vemos se trata de temas muy borgeanos y, de hecho, la Lección de anatomía abunda en comentarios y reflexiones sobre la literatura de Borges y la técnicas literarias introducidas por él que el autor serbio hace suyas o desarrolla a su manera. Kiš reconoce en esta obra una clara filiación con el autor argentino (entre otros, pero de forma muy especial) hasta tal punto que llega a incluir un artículo dónde Silvia Molloy ${ }^{9}$ comenta el uso de la cita en la poética borgeana para describir este procedimiento (fundamental tanto en Borges como en Kiš) en su propia obra.

En la Lección de anatomía Kiš confiesa que "Una tumba para Boris Davidovich utiliza ciertos procedimientos literarios que ha inaugurado ante todo Borges, y estos procedimientos no son otra cosa que la maestría al usar y trucar el material documental" ${ }^{10}$. Pero aparte de estos procedimientos (que encierran en realidad toda una poética), la adopción de una estructura narrativa similar y de ciertos materiales, lo cierto es que el nuevo programa estético que Kiš pone en marcha en Una tumba para B.D. muestra también un acercamiento a la literatura de Borges en un plano mucho más tangible, a un nivel puramente textual. En este libro el estilo se torna denso, el sentido se condensa y la utilización de los diferentes elementos sintácticos recuerdan a menudo la frase borgiana, aunque los materiales substanciales sean muy diferentes en los dos autores. Encontramos ya en este libro -que da inicio a la segunda etapa, más borgiana, de la obra de Kiš- una gran condensación de los contenidos, con frases concisas que apuntan la acción por medio de pinceladas impresionistas y se alejan de la descripción detallista típica de su primera época. Al leer muchas de las viñetas que componen esta novela parcelada en cuentos notamos fácilmente el influjo de repetidas lecturas de Borges, como si Kiš hu-

9 D. Kišs, Lección de anatomía, Barcelona 2013, pp. 120-123.

${ }^{10}$ Ibídem, p. 55. 
biera asimilado a la perfección, reformulándolo a su manera, ese método de la deducción, "una suerte de simbolismo narrativo" 11 , del que habla en su Lección de anatomía y cuya invención atribuye al autor de El Aleph. No obstante, el tono, el "espíritu" de la escritura del serbio es en general más serio y gra$\mathrm{ve}^{12}$ que en el argentino, donde el elemento lúdico se intuye como primordial. Como Borges, Kiš abunda también en la ironía, pero ésta no provoca ni una sonrisa, cuando proviene de la amarga experiencia centroeuropea del escritor yugoslavo. Aquí la ambigüedad del documento y la hipertrofia de citas (verdaderas o falsas), no ponen en duda la certitud de lo descrito sino que tienen que reforzar el carácter verídico de unos textos sólo en apariencia de ficción. Aquí lo inverosímil es si acaso la historia misma del estalinismo. Como indica Proguidis ${ }^{13}$ (1996), que por cierto considera a los dos autores como más bien opuestos, a pesar de las apariencias, "l'un (Borges) concerne l'homme en général. L'autre (Kiš) est»l'étude" d'une situation humaine, d'une situation historiquement déterminée" 14 . Y en este sentido, "como una suerte de éloge à J.L. Borges, Una tumba para Boris Davidovich es un contralibro de los de Borges", aclara Kiš en la Lección de anatomia ${ }^{15}$.

\section{La enciclopedia de los muertos}

Para su siguiente libro Kiš vuelve a dar un golpe de timón en su trayectoria acercándose más aún a la poética de Jorge Luis Borges. Publicada en 1983, La enciclopedia de los muertos recoge nueve cuentos escritos a finales de los 70 y principios de los 80 (años en los que se multiplican los 'borgesistas' croatas y serbios) y representa la eclosión del estilo borgiano en el conjunto de la obra de Kiš. Es con este libro que el autor de Subótica se hace más conocido a nivel internacional, sus libros se traducen a más de 20 lenguas y cuando aparecerá en Francia el apodo de 'Borges balcánico'. Realmente los estilos de ambos se acercan tanto aquí que algunos fragmentos parecen escritos por el mismo autor.

En La enciclopedia de los muertos Kiš se acerca a Borges no tan solo a nivel formal, sino también en el contenido, en la elección de los temas y los materiales. En la que él consideraba su obra más metafísica, Kiš vuelve su mirada hacia la ficción y se acerca en algunos de los cuentos a una literatura vagamente fantástica. Comienza aquí un gusto por las ambientaciones exóticas y míticas, así como por la temática mítico-religiosa y sobretodo mítico-histórica. En La en-

${ }^{11}$ Ibídem, p. 52.

12 A. Prstojević, op. cit.

${ }^{13}$ L. Proguidis, op. cit.

${ }^{14}$ Ibídem.

15 D. Kiš, op. cit., p. 56. 
ciclopedia de los muertos Kiš universaliza sus temas y los sitúa en tierras lejanas y en épocas pasadas, a menudo recreando escenarios estereotipados procedentes de episodios históricos o religiosos. En esta fase de la creación de Kiš muchos de los relatos adoptan las formas del mito, la leyenda o la parábola religiosa, pero como en el caso de muchos cuentos de libros como Ficciones, El Aleph, El libro de arena o la misma Historia universal de la infamia, esta forma de mito es utilizada en gran medida por motivaciones estéticas, como recipiente ideal para la prosa poética. Es más, tanto Borges como Kiš utilizan la bella forma del mito precisamente para poner de manifiesto su verdadera naturaleza, a menudo vacía de un verdadero centro de sentido, evidenciando a su vez sus altas posibilidades estéticas, que son las que le hacen tan atractivo y perdurable. Los dos escritores buscan desmitificar la Historia, la cultura y la religión partiendo del mismo mito que tan a menudo las sustenta (o quizás sería mejor decir: el episodio real pasado por el filtro de la mitificación) y a la vez demuestran la imposibilidad de llegar a un consenso de verdad, ya que ésta, si es que de alguna forma existe -cosa que también cuestionan- resulta inasible al hombre. De aquí la preocupación compartida por el carácter vulnerable y fácilmente manipulable de la verdad, consecuencia de la imposibilidad de su cognición, especialmente en el campo de la Historia y de la cultura. Eso les lleva a la denuncia de las continuas tergiversaciones, manipulaciones y hasta expolio que diferentes grupos o autores hacen del pasado histórico. Esto conduce tanto en Borges como en Kiš -en el serbio de una forma algo más explícita- a la preocupación por las posibilidades maléficas de la palabra escrita y muy especialmente del documento de cultura, nuevamente por su fragilidad y manipulabilidad, de la que irónicamente dejan constancia ambos autores desde la forma misma de sus relatos, infestados de diferentes formatos textuales, para-textos y notas bibliográficas apócrifas o de difícil comprobación.

Si bien estas reflexiones están ya muy presentes en Borges, será Kiš quien las explicite y explore con más persistencia. Mientras en Borges la utilización del mito se queda a veces en puro artificio estético, los cuentos de Kiš raramente participan de esta ligereza, de esta gratuidad lúdica. En La enciclopedia de los muertos la mayoría de los relatos giran en torno de los temas tratados más arriba, siempre resaltando la importancia del matiz en cualquier proceso cognitivo. Especialmente en lo referente a la materia histórica, Kiš abandona en este libro las esperanzas de dilucidación histórica que encontrábamos en Una tumba para Boris Davidovich (cabe, sin embargo, recordar el carácter testimonial y político de este último). Aunque temáticamente el elemento común de todos los relatos que hace que podamos hablar de novela posmoderna (a pesar de lo precario del término) es el tema de la muerte y el libro parece una especie de enciclopedia o compendio de temas relacionados con el 'más allá, este hilo es solo aparente y lo que da unidad al conjunto es más bien una amplia constelación de temas interrelacionados entre los que destacan los ya comentados en torno a las posibilidades de aprehensión de la verdad, la impor- 
tancia del matiz en el proceso cognitivo, el carácter vulnerable y manipulable de la Historia, el escepticismo en cuanto a las posibilidades de la cultura, etc.

Cuando la cuestión de la aprehensión de la verdad se acerca al tema del arte y la literatura, los cuentos de Kiš se convierten en pequeños tratados de teoría literaria, en especial de Hermenéutica, cosa que encontramos también de forma magistral en la obra de Borges. En este sentido, Kiš niega la posibilidad de una hermenéutica clásica y opta por una visión más moderna dónde las intenciones del autor quedan en segundo término. Esto le lleva a lanzar una feroz crítica en algunos de sus cuentos a los críticos literarios que pretenden ser demasiado exhaustivos y tajantes en el análisis de una obra literaria. Huelga recordar aquí que las diferentes formas de meta-literatura que Kiš introduce en sus cuentos aparecen, como en el caso de Borges, sólo de forma implícita, camufladas entre los avatares de la trama y la densidad de la prosa poética. De cualquier forma, la capacidad de convertir en ensayo un cuento, o viceversa, y la particular forma de desarrollar estéticamente una narrativa de motivación conceptual es algo que une de una forma muy especial a los dos autores.

Evidentemente, las diferentes tesis no aparecen de forma explícita, buscando la comprensión sólo de un lector aventajado. La compleja forma narrativa se presenta como un cedazo que rechaza al lector pasivo y busca la complicidad del lector 'tenebroso' - para utilizar un término encunado por el propio Borges- único lector posible que llegará a asir toda la carga conceptual que cada cuento de Kiš contiene. Como en el caso de la prosa de Borges, Kiš despliega en sus cuentos un amplio abanico de misterios y juegos destinados a implicar al lector culto y avisado.

Otra técnica que aparece constantemente en los relatos de los dos autores es también la contraposición de diferentes tesis y antítesis que dialogan entre sí para llegar a conclusiones a través de la dialéctica, para poner otro ejemplo.

Pero aparte de la apabullante presencia de técnicas, materiales y ambientaciones claramente borgianas, en La enciclopedia de los muertos también nos remite al autor de Ficciones la abundante intertextualidad (o hasta a veces cierta re-escritura, siguiendo así postulados también claramente borgianos) entre los cuentos de Kiš y los de Borges, en una obra en la que el serbio dialoga con el argentino sobre sus principales temas. Un caso claro sería el cuento La enciclopedia de los muertos (toda una vida) que al principio nos recuerda a La biblioteca de Babel, aunque esta reminiscencia borgiana inicial nos lleva a otro cuento dentro del cuento, como en unas cajas chinas, donde el gusto por la enumeración nos trae a la memoria otros cuentos de Borges como Funes el memorioso o El Aleph, para finalmente desembocar en una escritura esponjada y distendida, muy alejada de la condensación propia de los cuentos del argentino. A parte de este ejemplo, otros cuentos de Kiš nos remiten igualmente a diferentes momentos borgianos.

Para terminar, cabe remarcar que a pesar de toda la carga borgiana que contiene su obra, Kiš es poseedor de una poética propia que le hace inconfun- 
dible y la comparación con el argentino se justifica sobre todo por la calidad de la obra de ambos. El autor serbio supo absorber como nadie el legado inmenso del autor de Ficciones sin caer en la imitación de los elementos más superficiales, ambientales, de la poética borgiana. Como declaró en una ocasión su amigo Predrag Matvejević, Danilo Kišs, "gran admirador de Borges, escribió bajo su influencia y fue quizás uno de sus continuadores sin imitarlo servilmente como han hecho tantos"16.

\section{Bibliografía}

Alazraki J., La prosa narrativa de Jorge Luis Borges, Madrid 1968.

Brodsky J., Introduction [in:] D. Kiš, A tomb for Boris Davidovich, New York 1980. Cirlić-Straszyńska D., "Danila Kiša ogród, literatura", Literatura na Świecie 1988, $\mathrm{n}^{\circ} 198$.

Hemon A., "Reading Danilo Kiš", Context 2001, no 9.

Historia de las literaturas eslavas, ed. F. Presa, Madrid 1998.

Kiš D., Lección de anatomía, Barcelona 2013.

Morel J.-P., "Le cercle des assassins disparus", La Licorne 1998, no 44.

Proguidis L., Danilo Kiš, portrait de famille [en:] Danilo Kiš, romancier européen, L'Atelier du roman 1996, $\mathrm{n}^{\circ} 8$, http://www.vox-poetica.com/ecrivains/KIS/proguidis01.htm, Consulta: 7.03.2017.

Prstojević A., "Entre histoire et Histoire", L'Atelier du roman 1996-1997, nº 13.

Prstojević A., "Un certain goût de l'archive. Sur l'obsession documentaire de Danilo Kiš", Cahiers du CIM 2002, nº 6.

Quemain M.A., "La literatura hacia fin de siglo (Entrevista de Miguel Angel Quemain a Predrag Matvejević)", La jornada SEMANAL 1994, n 286, http://adastra.plgo.org/?page_id=91, Consulta: 6.03.2017.

Rizzante M., "De l'idéal encyclopédique" [en:] Danilo Kiš, romancier européen, L’Atelier du roman 1996, $\mathrm{n}^{\circ} 8$, http://www.vox-poetica.com/ecrivains/KIS/proguidis01.htm, Consulta: 7.03.2017.

Temps de l'Histoire, études sur Danilo Kiš, ed. A. Prstojević, Paris-Budapest-Torino 2003.

Vázquez M.E., Borges esplendor y derrota, Barcelona 1996.

Wierzbicki J., "Serbska proza”, Literatura na Świecie 1988, no 198.

${ }_{16}$ M.A. Quemain, "La literatura hacia fin de siglo (Entrevista de Miguel Angel Quemain a Predrag Matvejević)", La jornada SEMANAL 1994, no 286, http://adastra.plgo.org/?page_ id=91, Consulta: 6.03 .2017 . 